\title{
Tendencias en el número de médicos titulados anualmente en el Perú, 2007-2016: análisis de la variable género
}

\section{Trends in the number of physicians annually qualifying in Peru, 2007-2016: an analysis of gender variable}

Correspondencia Josué Ramírez-Orellana j.o.s.u.e_99@hotmail.com

Recibido: 07/06/2019 Aprobado: 21/06/2019 Arbitrado por pares

Citar como: Ramirez-Orellana J, Leon-Rivera H. Tendencias en el número de médicos titulados anualmente en el Perú, 2007-2016: análisis de la variable género. Acta Med Peru. 2019;36(2):179-80

\author{
Josué Ramírez-Orellana ${ }^{1}$, Herbert Leon-Rivera ${ }^{1}$
}

1 Escuela de Medicina Humana, Universidad Norbert Wiener. Lima, Perú.

Sr. editor. La carrera de medicina humana es una de las más solicitadas por los postulantes a las universidades en el país; esto sería reflejado en el aumento del número de escuelas académico profesionales creadas a lo largo de las últimas dos décadas; Peralta Cl et al. indicaron que para el periodo 2007-2016, el número de médicos titulados, ya sea en el país o en el extranjero, había aumentado [1]. No obstante, los autores no consideraron evaluar en su estudio la variable género, resultado que indicaría si la brecha de género se ha reducido en los últimos años. Por ejemplo, un estudio argentino encontró que dicha brecha se había reducido en el periodo 2003-2016 ${ }^{[2]}$. Es en este contexto que decidimos realizar este aporte.

A través de la historia se ha considerado a la profesión médica como una práctica reservada para los hombres, aunque esta creencia ha ido cambiando a través de los siglos. Según Fernández et al., desde fines del siglo XIX el interés de las mujeres por la medicina ha ido en aumento, a la par de un proceso de democratización que les permitió ejercer el derecho al sufragio, trabajar bajo iguales condiciones laborales, recibir educación y obtener otras conquistas sociales ${ }^{[3]}$.

En nuestro país está el caso de la Dra. Laura Rodríguez Dulanto (1872-1919) quien logró ser la primera mujer en juramentar como médico cirujano el 16 de septiembre de 1900, fecha que marcó un antes y después en la historia de la Medicina Peruana ya que permitió el acceso de las mujeres a la a comunidad médica de ese entonces ${ }^{[4]}$.

La diferencia y brechas de género también han sufrido cambios en el Perú. Castro y Yamada, en su estudio que evalúa datos poblacionales durante el periodo 2004-2008, indican que la brecha por sexo que se tenía históricamente ha ido disminuyendo al punto de no haber diferencia entre la cantidad de hombres y mujeres que concluyen con éxito el proceso educativo (educación básica y superior) ${ }^{[5]}$. Esta afirmación también se reflejaría en la profesión médica pues la diferencia entre colegiados hombres y mujeres durante el periodo 2007-2016 no ha superado las 600 personas.

Usando la base de datos del artículo original ${ }^{[1]}$, se contabilizó la variable género de los médicos colegiados anualmente en el Perú, 2007-2016 (Figura 1). Encontramos un predominio masculino en el número de colegiados. Entre los años 2007 y 2009 la relación de mujeres fue en aumento, presentándose incluso en el año 2009 un cambio en la razón a favor de las mujeres (1:1,49); sin embargo, posteriormente descendió y no se volvió a repetir este fenómeno. Además, en los años 2012 y 2014 la relación de colegiados varones y mujeres fue equitativa (1:1). 


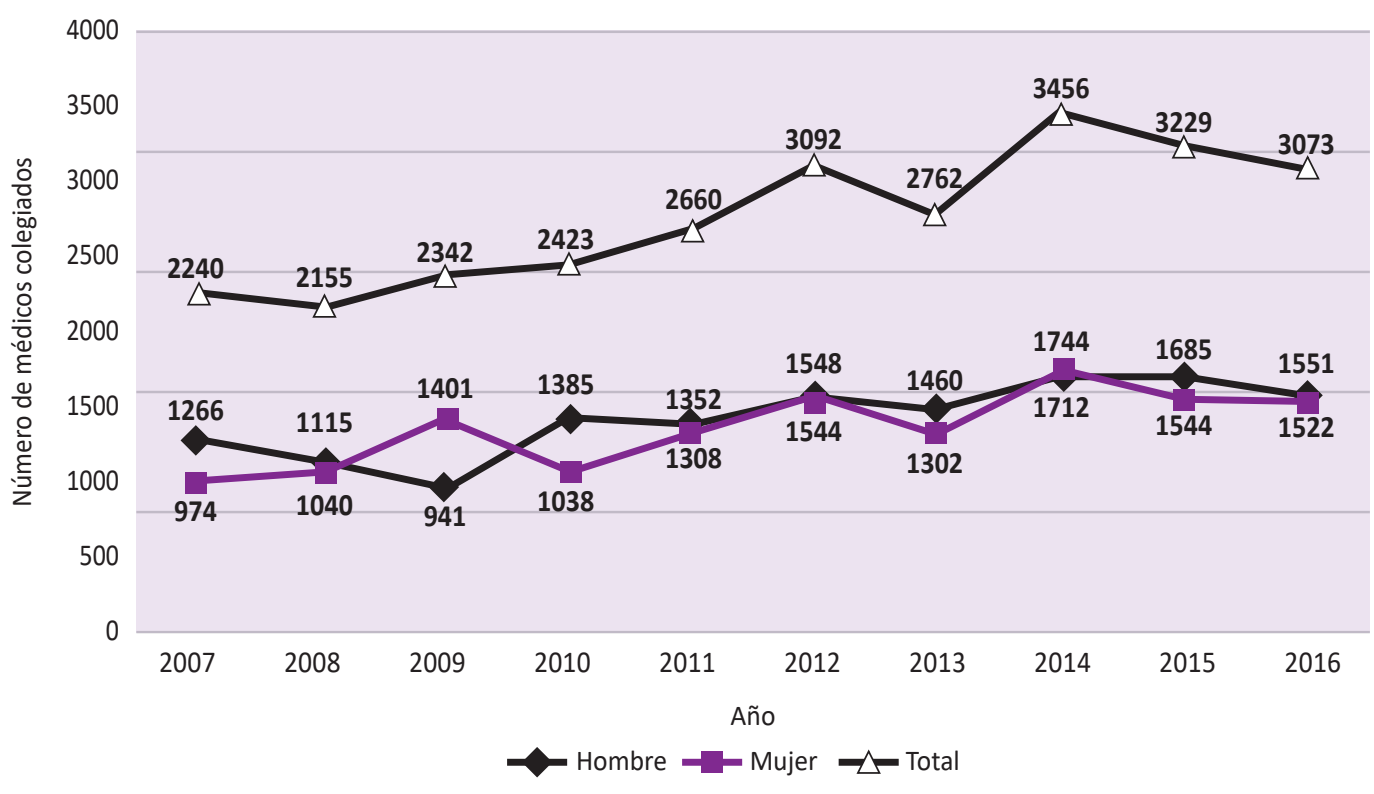

Fuente: Elaboración propia.

Figura 1. Tendencia en la colegiatura de médicos en el Perú (2007-2016) según género.

Concluimos que hubo un progresivo incremento en la tendencia de mujeres colegiadas desde el año 2007 hasta 2009, una mayor cantidad de colegiadas en este último año, aunque luego en el año 2010 hubo un descenso considerable - nunca se volvió a superar al número de colegiados hombres - y resultados equiparables en los años 2012 y 2014.

\section{REFERENCIAS BIBLIOGRÁFICAS}

1. Peralta $\mathrm{Cl}$, Garcia-Solorzano F, Zafra-Tanaka JH, Huapaya-Huertas OS, Taype-Rondan A. Tendencias en el número de médicos titulados anualmente en el Perú, 2007-2016. Acta Med Peru. 2019;36(1):19-25.

2. Programa de las Naciones Unidas para el Desarrollo. Género en el Sector Salud: Feminización y brechas laborales [Internet]. Buenos Aires: PNUD; 2018 [citado el 7 de febrero de 2019]. Disponible en: https://www.undp.org/content/ dam/argentina/Publications/Desarrollo\%20Humano/PNUD InformedeGenero_2018.04.04.pdf
Agradecimientos: Al Dr. Álvaro Taype Rondan por la colaboración con el acceso a los datos primarios y aclaración de algunos métodos del artículo original.

Financiamiento: Ninguno.

Conflicto de intereses: Ninguno.

3. Fernández C, Salinas A, Palacios M, Vargas C. Rol de la mujer médica: A propósito del Día Internacional de la Mujer. Acta Med Peru. 2012;29(1):12-13.

4. Pacora W. Laura Rodríguez Dulanto: primera médica cirujana peruana. Rev Peru Pediatr. 2007;60(1):67-8.

5. Castro J, Yamada G. Brechas étnicas y de sexo en el acceso a la educación básica y superior en el Perú [Internet]. Lima, Perú: Universidad del Pacífico; 2011 [citado el 7 de febrero de 2019]. Disponible en: http://repositorio.up.edu.pe/bitstream/ handle/11354/363/DD1104.pdf?sequence=1\&isAllowed=y 